Original Research Article

\title{
Evaluation of nephroprotective effect of Bryonia lacinosa on streptozotocin induced diabetic nephropathy in rats
}

\author{
Shruti S. Bhide*, Miteshkumar R. Maurya, Snehlata V. Gajbhiye, Firoz M. Tadavi
}

Department of Pharmacology and Therapeutics, Seth GS Medical College and KEM Hospital, Parel, Mumbai, Maharashtra, India

Received: 10 March 2017 Accepted: 01 April 2017

\section{*Correspondence to: Dr. Shruti S. Bhide, Email: shrutibhide72@ gmail.com}

Copyright: (C) the author(s), publisher and licensee Medip Academy. This is an openaccess article distributed under the terms of the Creative Commons Attribution NonCommercial License, which permits unrestricted noncommercial use, distribution, and reproduction in any medium, provided the original work is properly cited.

\begin{abstract}
Background: Ayurvedic literature indicated use of Bryonia laciniosa (BL) for metabolic abnormalities. However only one study evaluated Bryonia laciniosa seed ethanolic extract in streptozotocin-induced diabetes in rats and was found to have anti-hyperglycemic and anti-hyperlipidemic effects. The authors looked at the renal function test in addition and found that it prevents deterioration of renal function in rats. Hence it was interesting to find if Bryonia laciniosa had any protective action in streptozotocin induced diabetic nephropathy in rats.

Methods: Streptozotocin induced diabetic nephropathy model in wistar rats was standardised in phase 1 . In phase 2 animals were divided into 4 groups and diabetic nephropathy was induce with STZ. Vehicle Control group animals received CMC $0.5 \%$, Positive control group received enalapril $5 \mathrm{mg} / \mathrm{kg}$, Test group 1 received ethanolic extract of Bryonia laciniosa (EEBL) $250 \mathrm{mg} / \mathrm{kg}$ and Test group 2 received (EEBL) $500 \mathrm{mg} / \mathrm{kg}$ from 3rd day onwards till 6 weeks. Renal function, morphology and histopthological changes were evaluated.

Results: There was a significant reduction $(p<0.001)$ in the serum creatinine and BUN in both low and high dose EEBL groups. High dose of EEBL lowered raised MDA values significantly $(\mathrm{p}<0.001)$ and raised the GSH values $(\mathrm{p}<0.001)$. On histopathology, the high dose EEBL reversed nephropathic changes which were equivalent to enalapril.
\end{abstract}

Conclusions: Bryonia lacinosa in high doses $500 \mathrm{mg} / \mathrm{kg}$ has potential to reverse diabetic nephropathic changes induced in wistar rats.

Keywords: Bryonia lacinosa, Diabetic, Nephropathy, Streptozotocin

\section{INTRODUCTION}

A population based study conducted in India (2002-2005) has shown diabetic nephropathy accounts for $44 \%$ of end stage renal disease with mean age of 47 years and $58 \%$ of the affected were males. ${ }^{1}$ Among reported cases of chronic kidney disease, the most common cause was chronic glomerulonephritis that affects more than one third of patients, while diabetic nephropathy contributes to approximately $20 \%$ of all chronic kidney disease cases in India with median age of 44 years. To surprise only $<10 \%$ of all patients with end stage renal disease (ESRD) have a renal transplant due to cost constraints. ${ }^{2,3}$

Diabetic nephropathy a microvascular complication of diabetes mellitus is characterized by glomeruli capillary angiopathy. Like other microvascular complications, the pathogenesis of diabetic nephropathy is related to chronic hyperglycemia. The mechanisms by which chronic hyperglycemia leads to diabetic nephropathy though incompletely defined, involve the effects of soluble factors (growth factors, angiotensin II, endothelin and advanced glycation end products), hemodynamic alterations in the renal microcirculation and glomerular structural changes. The current management of diabetic nephropathy essentially involves control of glycemic status which includes comprehensive diabetic care, early detection of microalbuminuria and treatment with ACEinhibitors or ARBs with marginal success. ${ }^{4}$

Treatment of ESRD due to diabetic nephropathy requires dialysis and renal transplant contributing to major burden. 
There is a need to explore agents that can slow or halt progression of nephropathy. Ayurvedic literature indicates use of Bryonia laciniosa for metabolic abnormalities. ${ }^{5}$ However, in only one study which evaluated Bryonia laciniosa seed ethanolic extract and its saponin fraction in streptozotocin-induced diabetes in rats and was found to produce anti-hyperglycemic and antihyperlipidemic effects. The authors have also looked at the renal function test and found that it prevents deterioration of renal function parameters in rats. ${ }^{6}$ With this background it was interesting to find if Bryonia laciniosa had any protective action in streptozotocin induced diabetic nephropathy in rats.

\section{METHODS}

The permission of the institutional animal ethics committee (IAEC) was obtained prior to the initiation of the study (60/PO/ReBi/S/99/CPCSEA). The approval of the ethics committee was obtained under reference number AEC/11/2014. The study was carried out in 58 wistar rats of either sex, each weighing between 150-250 grams, randomly bred in the central animal house of the institution.

Animals were housed in the central animal house of our Institute. The study procedures and maintenance of the study animals were done in strict accordance with the CPCSEA guidelines.

\section{Study drugs}

- Streptozotocin extrapure (from Sisco Research Laboratories Pvt. Ltd. India) $60 \mathrm{mg} / \mathrm{kg}$ i.p in $0.1 \mathrm{M}$ sodium citrate buffer ( $\mathrm{pH} 4.5$ )

- ACE inhibitor drug $\rightarrow$ Enalapril (from SD Fine Chemicals) $5 \mathrm{mg} / \mathrm{kg}$ reno-protective dose in $0.5 \%$ $\mathrm{CMC}$ was given orally as positive control

- $0.5 \%$ Carboxymethycellulose (CMC) as vehicle for all drugs except streptozotocin
- Bryonia laciniosa seeds (95\% ethanolic extract from Akshay Pharma Remedies Pvt. Ltd. India) 250 $\mathrm{mg} / \mathrm{kg}$ and $500 \quad \mathrm{mg} / \mathrm{kg}$ in $0.5 \%$ carboxymethylcellulose (CMC).

\section{Study groups and procedures}

\section{Phase 1}

Diabetic nephropathy was induced in wistar rats after administration of $60 \mathrm{mg} / \mathrm{kg}$ of streptozotocin intraperitoneally (using cold, $0.1 \mathrm{M}$ citrate buffer, $\mathrm{pH}$ 4.5). Allocation of 18 wistar rats into normal control $(n=6)$ and disease control group $(n=12)$ was done.

\section{Procedure for phase 1}

The rats were kept fasting overnight in metabolic cages for 24 hours and on day 0, blood was collected from retro-orbital plexus and sent for estimation of baseline fasting glucose, serum creatinine and BUN levels. On day 0, 24-hour urine sample of these overnight fasted rats kept in metabolic cages was collected in glass tubes and sent for urinalysis for microalbumin. Rats with parameters within the normal range were selected for phase 1 standardization.

All biochemical parameters were done on day $0,3,7,14$, 28 ( 4 weeks), 42 ( 6 weeks). At the end of 6 weeks, the rats were euthanized by administering thiopentone sodium in the dose of $100 \mathrm{mg} / \mathrm{kg}$ intraperitoneally. Exploratory laparotomy was carried out to isolate both the kidneys and processed for morphology, histopathological examination, MDA and GSH estimation.

\section{Phase 2}

After screening, the rats were randomly allocated into 4 groups each containing 10 wistar rats $(n=10)$.

\section{Table 1: Distribution of animals in various groups.}

\begin{tabular}{|lll|}
\hline Groups (n= 10/ group) & $\begin{array}{l}\text { Inducing agent (administered i.p } \\
\text { after overnight fasting on day 1) }\end{array}$ & Drugs (administered daily orally from day 3) \\
\hline Vehicle control & Streptozotocin $60 \mathrm{mg} / \mathrm{kg}$ & $0.5 \%$ Carboxy methylcellulose \\
\hline Positive control & Streptozotocin $60 \mathrm{mg} / \mathrm{kg}$ & Enalapril $5 \mathrm{mg} / \mathrm{kg}$ \\
\hline Test group I & Streptozotocin $60 \mathrm{mg} / \mathrm{kg}$ & BL $250 \mathrm{mg} / \mathrm{kg}$ (low dose) \\
\hline Test group II & Streptozotocin $60 \mathrm{mg} / \mathrm{kg}$ & BL $500 \mathrm{mg} / \mathrm{kg}$ (high dose) \\
\hline
\end{tabular}

\section{Procedure for phase II}

The rats were kept fasting overnight in metabolic cages on day prior to starting study on day 0 . In the morning, at 8:00 am the blood $(2 \mathrm{ml})$ was collected from all rats from the retro-orbital vein using non- heparinized micro- hematocrit capillary tubes. Blood was sent for baseline estimation of fasting glucose, serum creatinine, BUN levels.

The animals were assigned randomly into four experimental groups, each containing 10 rats per group 
(disease control, positive control, high dose EEBL group, low dose EEBL group). The rats were numbered according to the groups they belonged and the cages were labelled appropriately. The rats were administered the inducing agent on Day 1 i.e. Streptozotocin (STZ) 60 $\mathrm{mg} / \mathrm{kg}$ single i.p dose in freshly prepared $0.1 \mathrm{M}$ citrated buffer adjusted to $\mathrm{pH}=4.4$.

All animals were administered STZ $60 \mathrm{mg} / \mathrm{kg}$ single dose i.p on day 1. After 72 hours of induction, blood $(2 \mathrm{ml})$ from retro-orbital vein was collected from all rats using non- heparinized micro-hematocrit capillary tubes to confirm the diabetes induction. Disease control or vehicle control group was administered only $1 \mathrm{ml}$ of $0.5 \%$ CMC oral dose, positive control received standard treatment with ACE-inhibitor enalapril $(5 \mathrm{mg} / \mathrm{kg})$ oral dose, while high dose group was orally fed with high dose (500 $\mathrm{mg} / \mathrm{kg}$ of EEBL) and low dose (250 mg/kg of EEBL) all drugs prepared in $0.5 \% \mathrm{CMC}$ as vehicle. At the end of the study blood was collected from retro orbital plexus to evaluate the parameters as mentioned below. Following which, rats were euthanized by administering thiopentone sodium in the dose of $100 \mathrm{mg} / \mathrm{kg}$ intraperitoneally.

Exploratory laparotomy was carried out within a period of 3-4 minutes and the kidney of the rat was dissected out and processed for histopathology, morphology, MDA and GSH levels.

\section{Variables assessed in the study}

\section{Following variables were measured in the study:}

a. Urine microalbumin

b. Kidney function tests (These were measured from the blood collected from the rats which was done before prescribing the drugs and at the end of the study)

- Serum creatinine

- $\quad$ Blood urea nitrogen (BUN)

c. Histopathological examination of the Kidney -score.

d. Random blood sugar (RBS)

e. Mean change in animal weight

f. Indicators of oxidative damage

- Kidney malondialdehyde (MDA)

- Kidney glutathione (GSH)

g. Morphological variables

- Kidney weight and volume (expressed as mg/100 gm body weight)

- Macroscopic changes - scarring, shrunken, paleness, fibrosis, haemorrhages.

\section{Statistical analysis}

Statistical analysis of data was done using the SPSS version 21 software for Windows. The normality of the data was assessed using the Kolmogorov-Smirnov test. The paired data in each group following normal distribution (parametric) was compared using paired t test while data with non-normal distribution (nonparametric) was compared using Wilcoxon-signed rank test.

The parametric data between two groups was compared using unpaired $t$ test while the non-parametric data between two groups was compared using Mann-Whitney test. Between the groups, the data which was normally distributed was compared using one-ANOVA test followed by post hoc Tukey's test while the data which was not normally distributed was compared using Kruskal-Wallis test. The histopathological scores between the groups were compared using Kruskal-Wallis test. The level of significance for each comparison in the analysis was calculated at 0.05 .

\section{RESULTS}

\section{Phase 1}
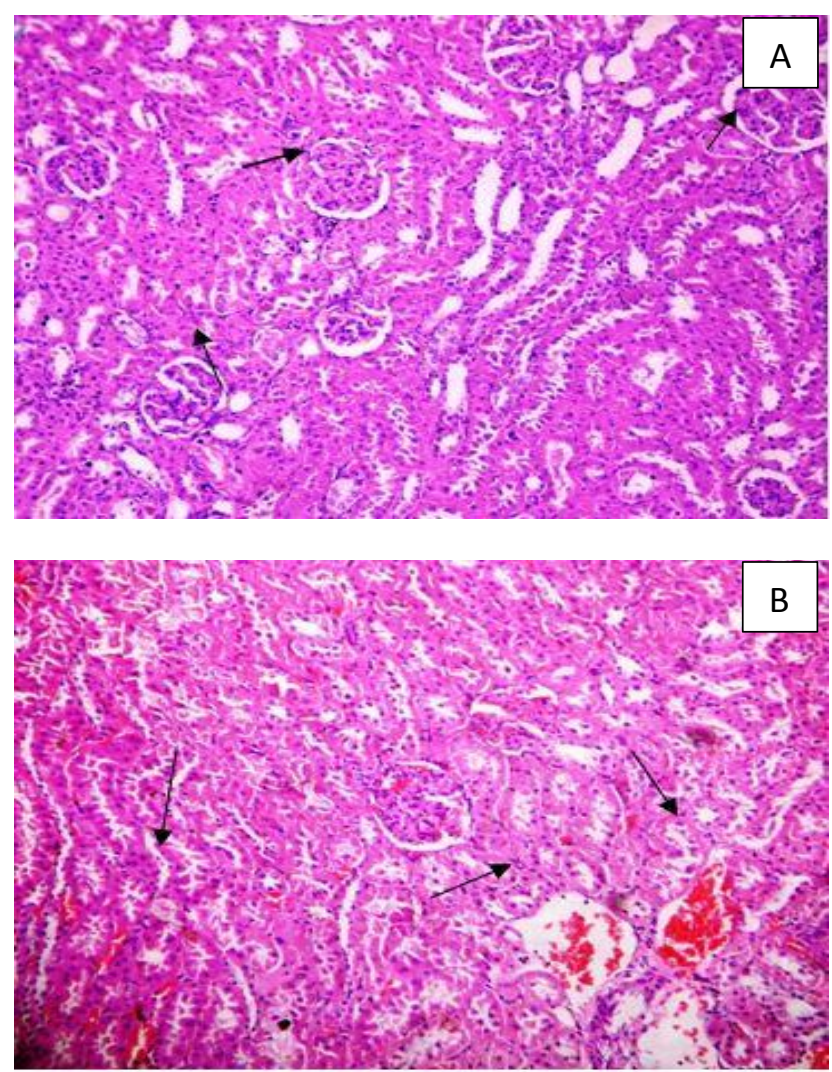

Tervaert et al score; (Median-range) (10x magnification).

Figure 1: Comparison of histopathological examination of kidney. (A) Normal control [0 (0-1)] (Arrow $\rightarrow$ normal glomerulus, and tubular epithelium); (B) Disease control [2 (1-2)] (Arrows: Mild vacuolar nephrosis, cloudy changes, cystic dilataion of tubules, mesangial expansion). 
At end of 6 weeks (42 days), urine analysis showed the presence of microalbumin (mean of $22.66 \mathrm{mg} / \mathrm{L}$ ) in disease control group $(n=12)$ compared with normal control group $(n=6)$ with absent microalbumin.

Disease control (STZ) group rats showed significant raised blood glucose level $341.78 \pm 186.35$ at 6 weeks compared with the normal control $118 \pm 6.03$ group $(\mathrm{p}<0.05)$. This significant derangement in serum creatinine levels continued at end of 6 weeks $(\mathrm{P}<0.0001)$ compared with normal control group. At end of 6 weeks the disease control (STZ) groups showed significantly raised blood urea nitrogen levels (BUN) compared with normal control group $(\mathrm{p}<0.0001)$. There was statistically significant increase in MDA $\mathrm{p}<0.001$ and fall in GSH $\mathrm{p}<0.001$ in the disease control group as compared to normal control animals. The median Tervaert et al scores of 1 (range 1-2) was observed in disease control as compared to 0 (range $0-1$ ) in the normal control.

\section{Phase 2}

We observed a significant decrease in the urine microalbumin levels at the end of 6 weeks in positive control group as compared to disease control $(\mathrm{p}<0.001)$ as shown in Table 2. High dose EEBL (500 mg/kg) significantly reduced urine microalbumin levels compared with disease control group $(\mathrm{p}<0.001)$.

Table 2: Comparison of urine microalbumin level.

\begin{tabular}{|lll|}
$\begin{array}{l}\text { Groups } \\
(\mathbf{n = 1 0 /} \text { group) }\end{array}$ & $\begin{array}{l}\text { Day 0 } \\
\text { (baseline values }\end{array}$ & $\begin{array}{l}\text { Day } 42 \text { (post } \\
\text { ST dose) }\end{array}$ \\
\hline $\begin{array}{l}\text { Disease control } \\
\text { (STZ+ 0.5\% CMC) }\end{array}$ & Not detected & $27.77 \pm 7.2$ \\
\hline $\begin{array}{l}\text { Positive control } \\
\text { (STZ+ Enalapril) }\end{array}$ & Not detected & $2.42 \pm 0.78^{*}$ \\
\hline $\begin{array}{l}\text { STZ+ low dose } \\
\text { EEBL }\end{array}$ & Not detected & $12.46 \pm 1.79$ \\
\hline $\begin{array}{l}\text { STZ+ high dose } \\
\text { EEBL }\end{array}$ & Not detected & $3.53 \pm 1.58^{*}$ \\
\hline P value & - & $\mathrm{P}<0.001$ \\
\hline
\end{tabular}

One way ANOVA with post hoc tukey test, ${ }^{*} \mathrm{p}<0.0001$ versus disease control

We observed significant decrease in blood glucose levels on day 3 post STZ administration (day 1) in positive control, high dose EEBL group and low dose EEBL group compared with disease control group $(\mathrm{p}<0.05)$ as shown in Figure 2. This fall in blood glucose continued till the end of 6 weeks.

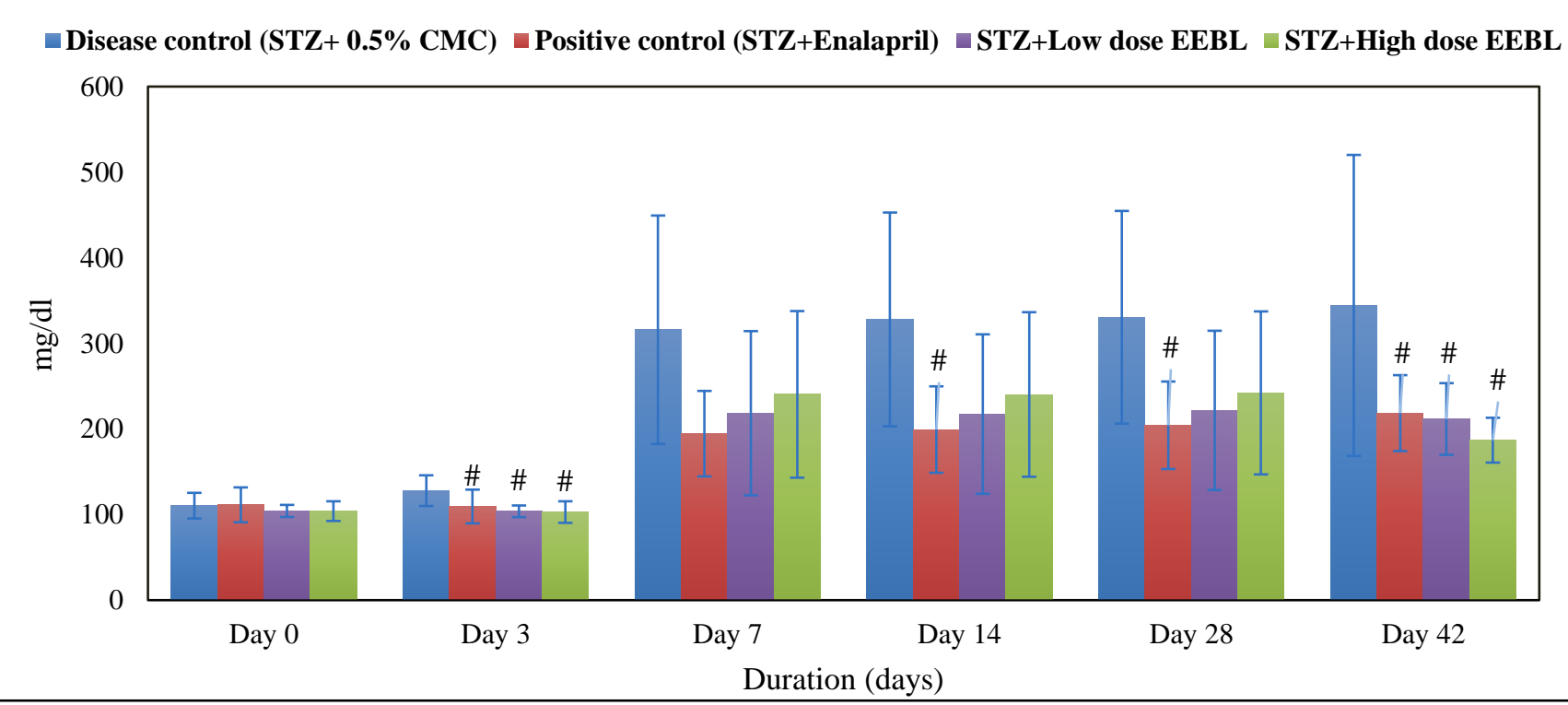

One way ANOVA with post hoc Tukey test, $\# \mathrm{p}<0.05$ versus disease control

Figure 2: Comparison of blood glucose levels.

A significant decrease in the serum creatinine levels was observed in positive control and high dose EEBL groups as compared to disease control group $(\mathrm{p}<0.001)$ as shown in Figure 3.

While on day 14, 28 and 42, there was statistically significant decline in the serum creatinine levels of positive control, high and low dose groups compared with that of disease control group $(\mathrm{p}<0.05)$.

A significant decrease in the blood urea concentration was observed at the end of 6 weeks, in the Low dose and high dose EEBL groups and the positive control groups as compared to disease control group $(\mathrm{p}<0.001)$ as shown in Figure 4. 


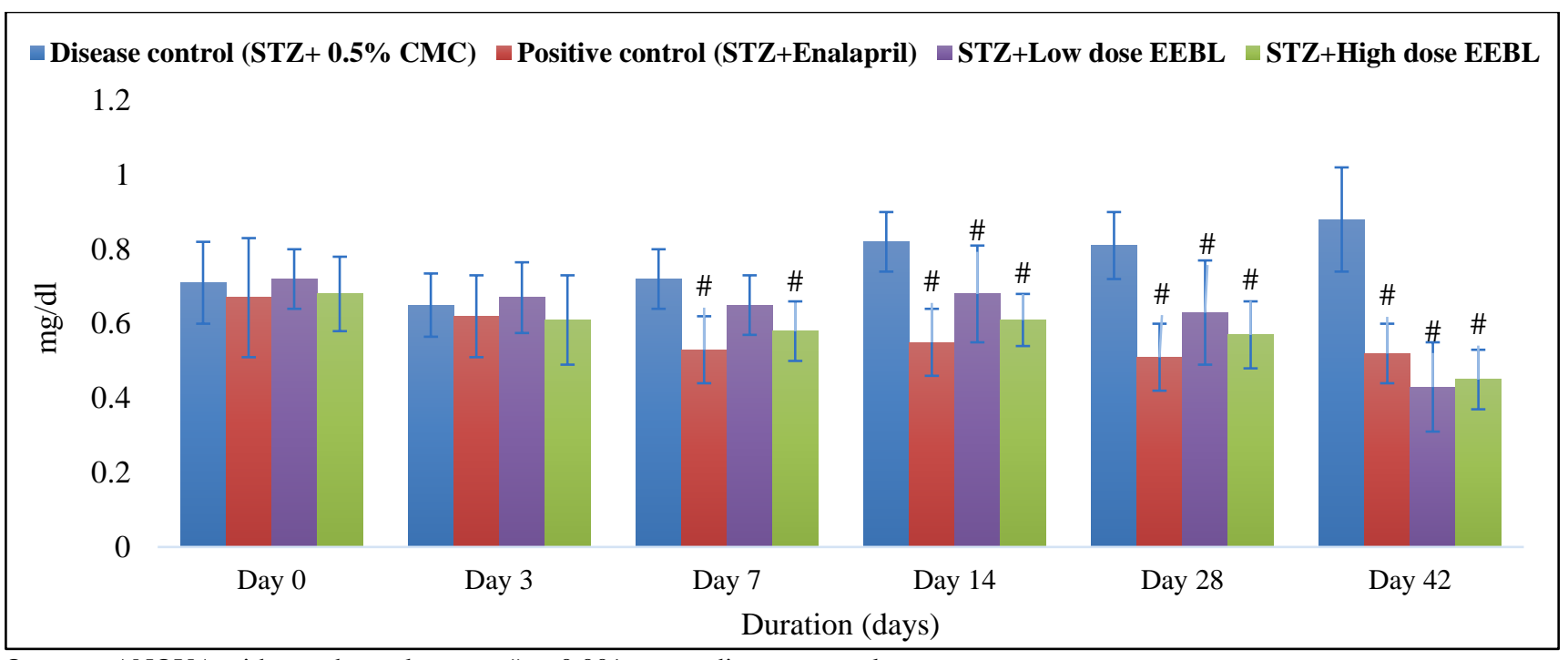

One way ANOVA with post hoc tukey test, \# $\mathrm{p}<0.001$ versus disease control

Figure 3: Comparison of serum creatinine levels.

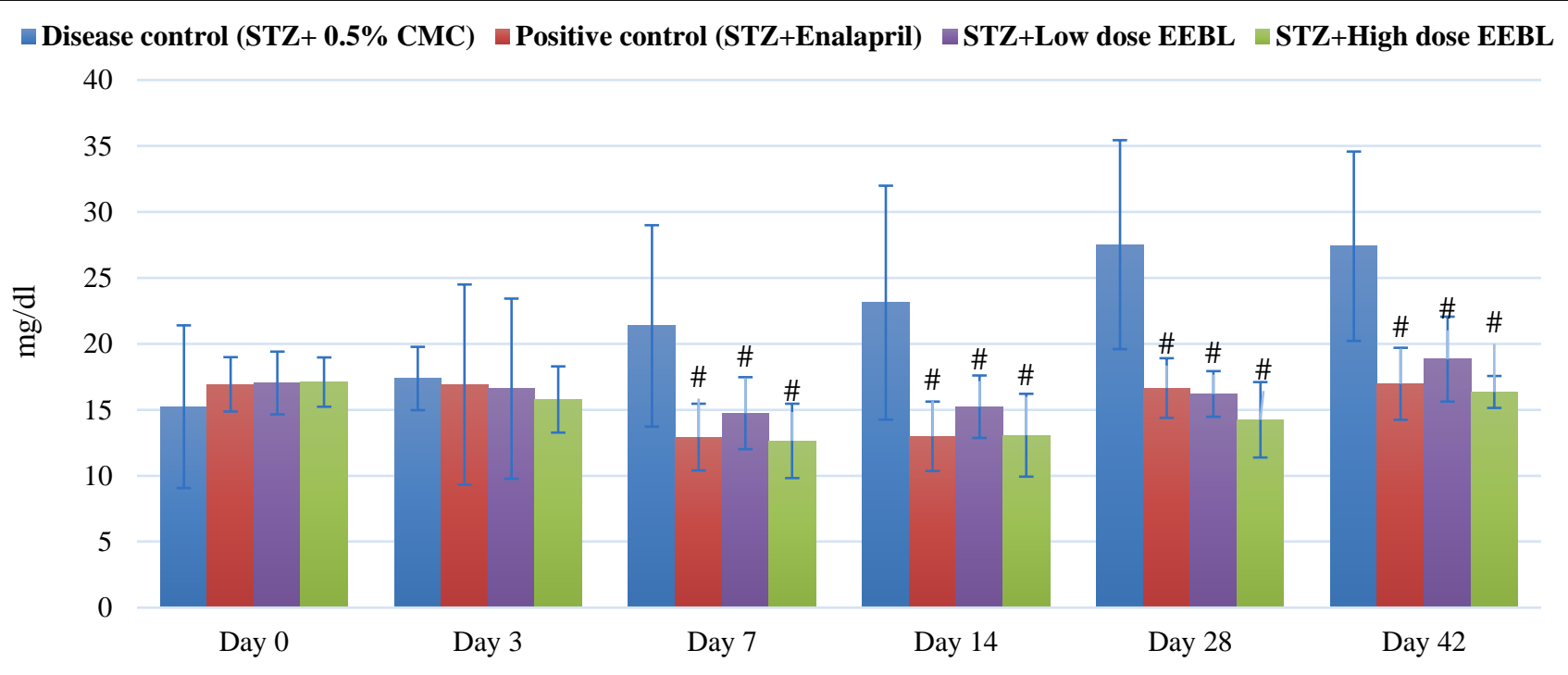

Values are mean \pm SD. One way ANOVA with post hoc Tukey test, $\# \mathrm{p}<0.001$ versus disease control

Figure 4: Comparison of blood urea nitrogen (BUN) levels.

The kidney MDA levels showed significant decrease in the positive control group and high dose EEBL group compared to the disease control group $(\mathrm{p}<0.0001)$ and low dose EEBL group ( $\mathrm{p}<0.05)$.

While GSH levels significantly increased in the positive control group and high dose EEBL group compared to the disease control group $(\mathrm{p}<0.05)$ as shown in Table 3 .

A significant reduction in the mean kidney volume was observed in disease control and low dose EEBL group while positive control and high dose EEBL group, a higher mean kidney volume was observed $(\mathrm{p}<0.05)$ as shown in Table 4.
Table 3: Comparison of blood MDA and GSH levels.

\begin{tabular}{|lll|}
$\begin{array}{l}\text { Kidney antioxidants } \\
\text { (n=10/group) }\end{array}$ & MDA & GSH \\
\hline $\begin{array}{l}\text { Disease control } \\
\text { (STZ+ 0.5\% CMC) }\end{array}$ & $302.6 \pm 47.47$ & $0.97 \pm 0.38$ \\
\hline $\begin{array}{l}\text { Positive control } \\
\text { (STZ+ Enalapril) }\end{array}$ & $203.67 \pm 25.39 *$ & $1.73 \pm 0.13^{*}$ \\
\hline STZ+ High dose EEBL & $213.05 \pm 33.56^{*}$ & $1.21 \pm 0.23^{*}$ \\
\hline STZ+ Low dose EEBL & $284.09 \pm 63.12$ & $1.19 \pm 0.54$ \\
\hline P value & $<0.0001$ & $<0.05$ \\
\hline
\end{tabular}

Values are mean \pm SD. One way ANOVA with post hoc tukey test, ${ }^{*} \mathrm{p}<0.05$, versus disease control 
Table 4: Comparison of mean kidney volume.

\begin{tabular}{|lllll|}
\hline Animal groups (n=10/group) & Disease control & Positive control & High dose EEBL & Low dose EEBL \\
\hline Mean kidney volume (day 42) & $3.07 \pm 0.48$ & $3.76 \underline{ \pm 0.97 *}$ & $3.6 \pm 0.69$ & $3 \underline{+0.41}$ \\
\hline & $\mathrm{p}<0.05$ & & & \\
\hline
\end{tabular}

Values are mean $\pm \mathrm{SD} ; * \mathrm{p}<0.05$, versus disease control

No significant changes in kidney weight were observed as shown in Figure 5.

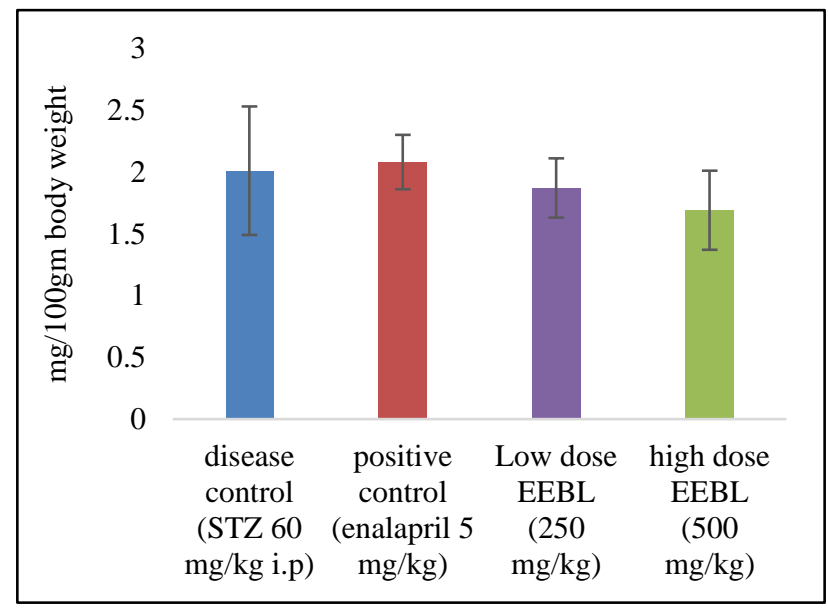

Values are mean \pm SD. One way ANOVA with post hoc tukey test

Figure 5: Comparison of mean kidney weight at day 42.

There was significant increase in mean body weight of positive control group as compared to other groups ( $\mathrm{p}$ $<0.05$ ) as shown in Figure 6.

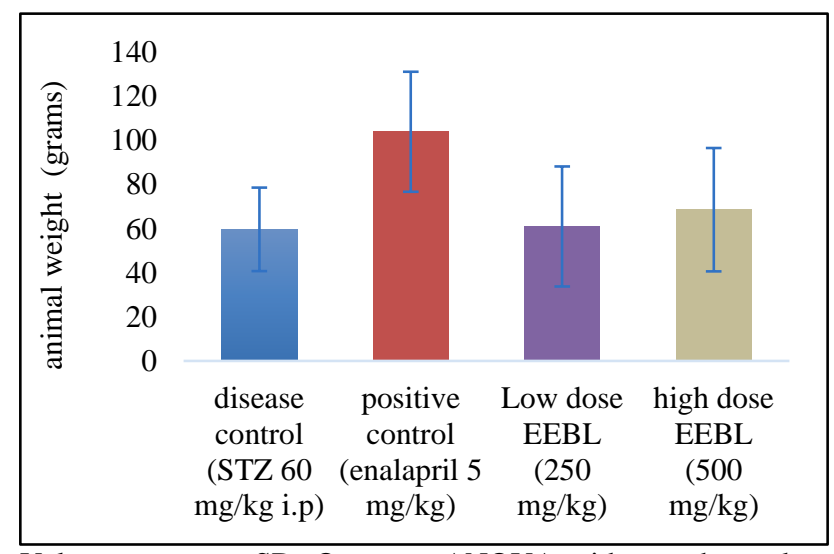

Values are mean \pm SD. One way ANOVA with post hoc tukey test, $\# \mathrm{p}<0.05$, versus disease control

Figure 6: Comparison of mean change in rat weight.

The median Tervaert et al, scores in the disease control, positive control, high dose EEBL and low dose EEBL group were 3,1 (range 1-2), 1 (range 1-2) and $3(1-3)$ respectively as shown in Table 5 and Figure 7.

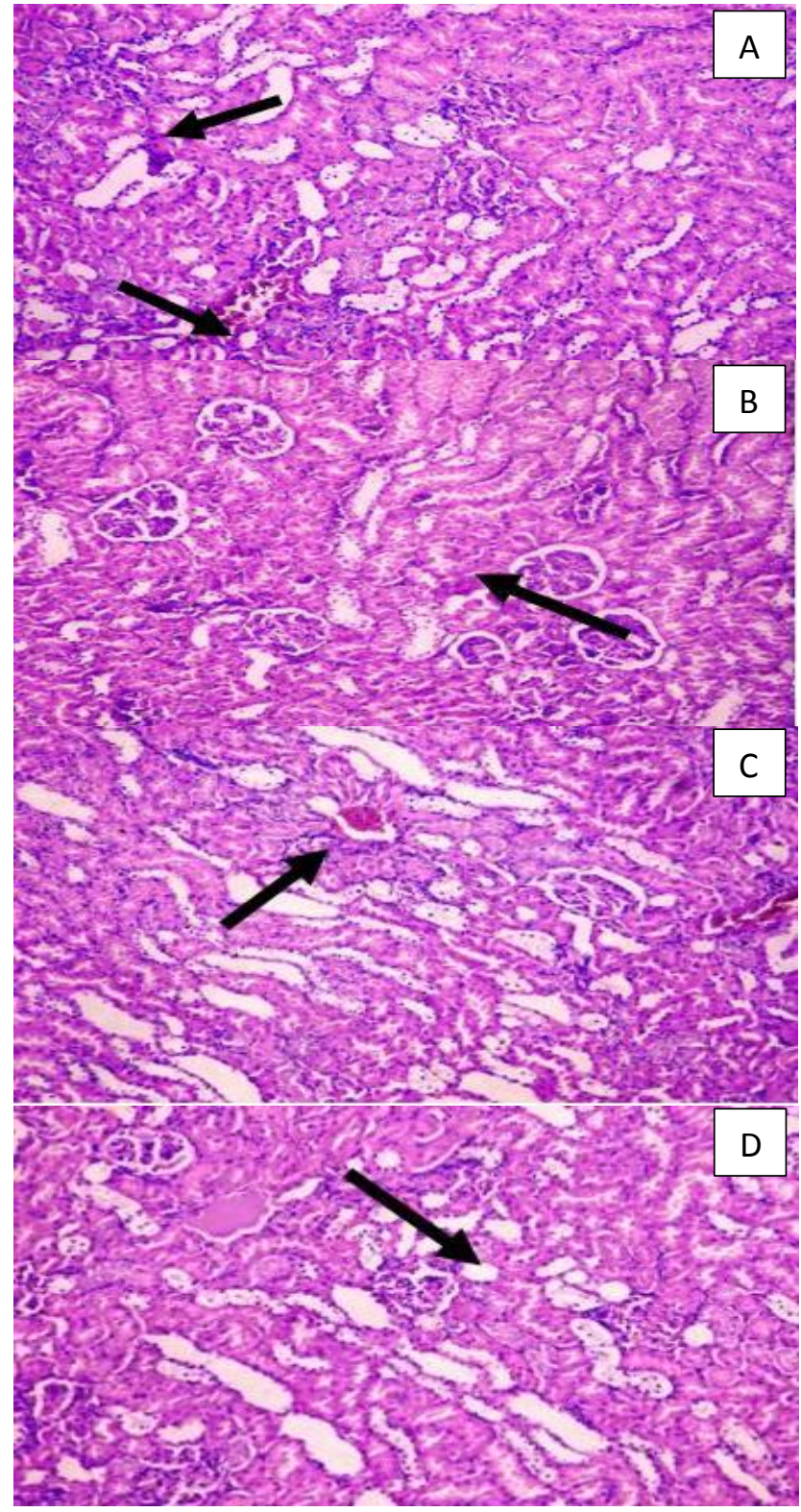

Magnification 10X

Figure 7: Histopathology of kidney in various groups. (A) Disease control [3 (range 3-3)]: (Arrows: cystic dilatation of tubules with granular degeneration, moderate to severe mesangial expansion); (B) Positive control (enalapril 5mg/kg) [1 (1-2)] (Arrows: Mild vacuolar changes); (C) Low dose EEBL [3 (range 1-3)] (Arrows: cystic dilatation of tubules with granular degeneration) with moderate to severe mesangial expansion; (D) High dose EEBL [1 (range 1-2)] (Arrows: mild vacuolar changes). 
Table 5: Comparison of histopathological examination of kidney.

\begin{tabular}{|ll|}
\hline Groups (n=10/group) & Histopathological grades \\
\hline Disease control & 3 \\
\hline Positive control & $1^{*}$ \\
\hline High dose EEBL & $1^{*}$ \\
\hline Low dose EEBL & 3 \\
\hline
\end{tabular}

Tervaert et al score; (Median-range)

On comparing the Tervaert et al, scores in the groups using Kruskal-Wallis test, it was found that the Tervaert et al, scores in the positive control and high dose EEBL group were significantly lower than the disease control group $(\mathrm{p}<0.001)$.

\section{DISCUSSION}

In the present study, we observed that ethanolic extract of Bryonia laciniosa seed in the dose of $500 \mathrm{mg} / \mathrm{kg}$ showed renoprotective effect. The effect of high dose of EEBL $(500 \mathrm{mg} / \mathrm{kg})$ and low dose EEBL group $(250 \mathrm{mg} / \mathrm{kg})$ on BUN and serum creatinine were comparable with ACE inhibitor. Patel SB et al observed a similar reduction in BUN and serum creatinine in streptozotocin induced diabetic rats which they concluded to be due to antihyperglycemic action. But in this previous study, effect of EEBL on diabetic nephropathy was not evaluated. ${ }^{6}$ Hence we decided to evaluate the effect of EEBL on diabetic nephropathy in wistar rats. SB Patel et al. in addition found anti-hyperlipidemic effects in the same model. We used this model as it has similarity with early stages of diabetic nephropathy found in humans. ${ }^{7}$

The current therapy includes use of ACE inhibitors and ARBs which have shown to halt the progression of diabetic nephropathy. The mechanism by which it manifests this action is due to reduction of microalbuminuria. Further search for prevention in this condition had not been successful. Since EEBL showed a positive effect in STZ induced diabetic wistar rats we considered this agent to be most appropriate to study in nephropathy.

We observed a fall in serum blood glucose levels at the end of study period which is similar to that observed by SB Patel et al. In the present study, we observed a fall in urine microalbumin levels with higher dose $(500 \mathrm{mg} / \mathrm{kg})$ of EEBL. Therefore, EEBL's renoprotective effect could be attributed to this action which is similar to ACEinhibitors. STZ induces diabetic nephropathy by generating oxidative stress. In most studies of the herbs shown to produce renoprotective effect, it has been proposed to be exhibited by their antioxidant mechanisms. EEBL similarly exhibited antioxidant action which was evaluated by estimating MDA and GSH. This antioxidant action may also be responsible for its observed renoprotective effect. The renoprotective effect produced by higher dose of EEBL was further strengthened by histological findings and morphological changes.
In a study conducted by Patel et al, to determine the effect of ayurvedic drugs in management of diabetic nephropathy a mixture of Gokshuradi Guggulu, Bhumyamalaki, Vasa and Shilajatvadi Vati given for 2 months was associated with a significant improvement in the renal function. ${ }^{8}$

The list of plant drugs being explored for diabetic nephropathy is extensive. Many of them exert their renoprotective actions either due to its antidiabetic potential and antioxidative mechanism. Herbs such as Terminalia chebula, Vitis vinifera, Curcuma longa, Silybum adans, Camellia sinensis, Benincasa cerifera, are coming up with novel. Action that can ameliorate diabetic nephropathy symptoms includes other mechanism includes inhibition of formation of advanced glycation products such as with Polygonatum odoratum. It would be worthwhile to study the action of EEBL on advanced glycation products and effect on over-expression of transforming growth factor- beta (TGF-beta 1), connective tissue growth factor (CTGF), fibronectin (FN) and plasminogen activator inhibitor 1 (PAI-1) in renal cortex and mucopolysaccharides accumulation in renal cortex.

\section{CONCLUSION}

The present study demonstrated renoprotective effect of EEBL in the model of STZ induced diabetic nephropathy. This action could be due to its antioxidant mechanism. Further studies are needed to confirm this action by including higher doses and study of other possible mechanisms of action. In addition, EEBL could also be evaluated for its potential renoprotective effect in other types of nephropathy.

\section{ACKNOWLEDGEMENTS}

Authors would like to thanks, Akshay Pharma Remedies Pvt. Ltd. India for providing Ethanolic extract of Bryonia Lacinosa.

Funding: Diamond Jubilee Society Trust, Seth GS Medical College and KEM Hospital Mumbai-400012. Conflict of interest: None declared

Ethical approval: The study was approved by the Institutional Ethics Committee 60/PO/ReBi/S/99/CPCSEA

\section{REFERENCES}

1. Modi G, Jha V. The incidence of end-stage renal disease in India: a population-based study. Kidney Internat. 2006;70(12):2131-3.

2. Sakhuja V, Kohli HS. End-stage renal disease in India and Pakistan: incidence, causes, and management, Ethn Dis Spring. 2006;16(2):S2-20-3.

3. Agarwal SK, Dash SC, Irshad M, Raju S, Singh R, Pandey RM. Prevalence of chronic renal failure in 
adults in Delhi, India. Nephrol Dial Transp. 2005;20:1638-42.

4. Longo, Fauci, Kasper, Houser, Jamson, Loscalzo, Harrison's principle of internal medicine. 2015;19(2):2422-6.

5. Mosaddik MA, Ekramul HM, Abdur RM. Goniothalamin from Bryonopsis laciniosa Linn (Cucurbiataceae). Biochem Syst Ecol. 2000;28(10):1039-40.

6. Patel SB, Santani D, Shah MB, Pate VS. Antihyperglycemic and anti-hyperlipidemic effects of Bryonia laciniosa Seed extract and its saponin fraction in streptozotocin-induced diabetes in rats. J Young Pharma. 2016;4(3):171-6.
7. Fioretto P, Mauer M, Diabetic nephropathychallenges in pathologic classification, nature reviews. Nephrol. 2010;6:508-10.

8. Patel K, Gupta S, Shah N. Effect of Ayurvedic management in 130 patients of diabetic nephropathy. Ayu. 2011;32(1):55-8

9. Shafi S, Tabassum N, Ahmad F. Diabetic nephropathy and herbal medicines. Internet $\mathbf{J}$ Phytopharmacol. 2012;3(1):10-7.

Cite this article as: Bhide SS, Maurya MR, Gajbhiye SV, Tadavi FM. Evaluation of nephroprotective effect of Bryonia lacinosa on streptozotocin induced diabetic nephropathy in rats. Int J Basic Clin Pharmacol 2017;6:1193-200. 